\title{
NOD, SHRUG, FROWN: UM ESTUDO DO SIGNIFICADO DO LÉXICO POR MEIO DA TRADUÇÃO ${ }^{1}$
}

\section{Maria Candida Bordenave}

O professor de tradução tem um lugar privilegiado em termos de observação linguística. O termo "privilegiado" refere-se apenas a que ele dispõe de um vantage point ao observar o comportamento das línguas.

A atividade da tradução coloca frente a frente dois códigos linguísticos:

$1^{\circ}$.) na sua totalidade comunicativa e não recortada em padrões isolados e níveis linguísticos específicos para fins de aprendizado;

$2^{\circ}$.) a situação de confronto e oposição dos dois códigos se faz de forma especial: o texto original - para o nosso exemplo, em inglês - provoca a criação de outro texto - o texto em português - os dois íntima e irrevogavelmente unidos, como irmãos siameses, pelo significado único;

$3^{\circ}$.) pelo fato de que a atividade tradutora trabalha com os elementos formais à procura do significado exato, em detalhe, ela opera todo o tempo com forma e significado, procurando penetrar na articulação e na vinculação entre os dois, processo no qual tornam-se nítidas as características, recursos e recortes de uma língua em relação à outra.

Assim, tal processo tem para nós, professores de tradução, uma função semelhante à das lâminas com matéria viva que o cientista examina através do microscópio. Esperando que a comparação seja mais elucidativa do que confusionista, o que quero dizer é que na tradução temos a oportunidade de ver e observar a língua viva em seu dinamismo, sua multiplicidade de formas e sentidos, sua complexidade e "inovatividade".

O trabalho que ora apresentamos tem como objetivo a descoberta do significado de alguns itens lexicais através da tradução. Foi feito com base em um número limitado de exemplos e constitui uma abordagem inicial que poderá se transformar em estudo mais abrangente. De forma alguma pretende ser um estudo completo ou propor soluções terminadas para essas formas, mas apenas apresentar alguns dados encontrados a partir

\footnotetext{
${ }^{1}$ N.E.: Comunicação apresentada no I Encontro Regional de Professores Universitários de Língua Inglesa, realizado na PUC-Rio em 1986.
} 
de problemas bastante concretos surgidos na prática de tradução em sala de aula com referência a nod, shrug e frown.

Partimos da observação linguística, procurando verificar nos exemplos coletados o seu comportamento sintático e a sua relação com o significado, recorrendo a informações pragmáticas quando necessário.

Por que tais itens lexicais suscitam problemas na prática da tradução, foi a questão que nos levou a observar as suas diversas ocorrências.

Logo de início constatamos alguns fatos:

$1^{\circ}$ ) trata-se de itens lexicais de ocorrência muito frequente em textos em que a interação dos participantes tem papel relevante;

$2^{\circ}$.) a língua portuguesa não tem correspondentes únicos com o mesmo significado. A equivalência, nem sempre satisfatória, é feita através de expressões longas, nem sempre apropriadas ao estilo e registro do texto;

$3^{\circ}$.) esses itens expressam movimentos corporais, gestos, que têm papel relevante na produção do sentido naquele tipo de texto, pois na maioria das vezes têm um propósito, revelam uma atitude ou estado mental, ou mesmo uma pluralidade de propósitos. Raramente o gesto é pura e simplesmente um movimento corporal.

A combinação destes três fatos — a frequência de ocorrência, a ausência de itens lexicais simples equivalentes em português e o seu conteúdo semântico complexo - é responsável pelos problemas encontrados pelos estudantes de tradução. Tais problemas se referem ao desconhecimento das potencialidades semânticas do item e à dificuldade de encontrar uma equivalência satisfatória exigida pelo contexto semântico e pragmático.

Limitamo-nos a observar as formas verbais, visto que as formas nominais encontradas têm o mesmo comportamento semântico e são facilmente redutíveis a formas verbais.

De início, três perguntas básicas orientaram nossa análise dos exemplos coletados:

$1^{\circ}$.) qual o comportamento sintático do termo em questão?

$2^{\circ}$.) sendo verbos que ocorrem principalmente na interação, eles surgem sempre como resposta ao interlocutor, ou não?

$3^{\circ}$.) qual o significado do gesto naquele contexto específico? 
Nod foi o item que se apresentou como o mais complexo e consequentemente como o mais difícil de traduzir. Dos três é o de maior ocorrência, sendo coletados cerca de 40 exemplos nos textos analisados.

Tem um componente sintático variável. É em geral intransitivo, mas pode também ocorrer como transitivo.

1. intransitivo. Exemplos:

(1) He nodded and sighed.

(2) “See?"

The boy nodded and the man...

(3) "You're certain of this translation?"

She nodded.

1.1 Ainda como intransitivo, ocorre também com muita frequência acompanhado de um adjunto adverbial que ajuda a definir seu significado.

(4) He nodded doubtfully.

(5) The man nodded reassuringly.

(6) He saw Madame V. nod understandingly and glance at the old man.

1.2 Também ocorre com um adjunto que é o destinatário - ser animado, em geral humano - da mensagem representada pelo gesto.

(7) The man was crooking his finger and nodding to him.

(8) He smiled and nodded to the colonel, who came immediately.

(9) The man was nodding at him soberly.

2. transitivo. Exemplos:

(10) He nodded his sympathy.

(11) The Superintendent nodded his comprehension.

(12) D. balanced the poker in his hand, nodded his satisfaction and walked over to the door.

(13) "Then, shall we go?"

The Major, who had finished his breakfast some time ago, nodded assent and rose.

Quando nod adquire transitividade, seu objeto direto tem o mesmo papel que os adjuntos adverbiais acima mencionados, o de definidor do componente psicológico do significado do verbo.

Do ponto de vista semântico, nod pode exprimir: 
- movimento físico, isto é, a ação de mover verticalmente a cabeça uma ou várias vezes; ou

- movimento físico $+x$, onde $x$ significa um propósito, uma atitude mental por detrás do gesto.

Podemos classificar os exemplos coletados segundo o significado definido pelo contexto linguístico ou situacional. Nos grupos encontrados, observamos se nod ocorre ou não em interação, como também seu comportamento sintático e a sua ocorrência ou não em resposta a um interlocutor.

1. significado: apenas movimento físico. Intransitivo. Não faz parte de interação.

1.1. movimento involuntário de quem dorme sentado.

(14) He sat nodding by the fire.

1.2. movimento de ser inanimado metaforicamente semelhante ao exemplo acima.

(15) The plumes that nodded on his helmet...

2. significado: movimento físico $+x$. Faz parte de interação.

2.1. movimento involuntário. Significado de $x$ é pouco definido, podendo ser interpretado como um simples reconhecimento da presença do interlocutor. Intransitivo com ou sem ajunto adverbial. Não ocorre como resposta ao interlocutor.

(16) The man was nodding at him soberly.

(17) The woman still stood watching him. He nodded to her and, motioning to the house, went towards the house.

(18) Madame V. listened bravely to the translation, then nodded and began to speak.

2.2. $x$ = cumprimento. Intransitivo com ou sem adjunto adverbial. Não ocorre como resposta ao interlocutor.

(19) "How is your daughter?"

"She's fine."

Tom nodded and left.

(20) The girl no more than nodded and smiled.

(21) "Very good, sir", D. said and nodded respectfully to Dickie.

(22) Nodding to S., Bill went into the hall and up the stairs. 
2.3. $x$ = chamamento ou ordem. Intransitivo. Não é resposta.

(23) He nodded briefly and a sad-faced young man came into the room.

2.4. $x=$ concordância, aceitação. Intransitivo. Ocorre como resposta ao interlocutor. Foi o grupo mais numeroso encontrado.

(24) "Let me know when you're in position."

R. nodded and started down the road.

(25) "Care to dance?"

And she would glance across at her friends and then nod and walk with him onto the floor.

(26) "Just do what I tell you. Do you understand?"

She nodded not looking at him.

(27) “He’s dead?” asked B.

The doctor nodded.

2.5. $x=$ outra atitude mental ou sentimento expresso pelo adjunto adverbial ou pelo objeto direto quando transitivo. Ocorre como resposta ao interlocutor.

(4) He nodded doubtfully.

(5) The man nodded reassuringly.

(6) He saw Madame V. nod understandingly and glance at the old man.

(10) He nodded his sympathy.

(11) The Superintendent nodded his comprehension.

(12) D. balanced the poker in his hand, nodded his satisfaction and walked over to the door.

2.6. $x=$ reforço a algo que foi dito ou pensado pela própria pessoa, isto é, concordância consigo mesmo.

(28) "You smell that?"

"Jasmine." She nodded. "It was used to sweeten the journey of royalty into the afterworld."

(29) Mr. B. stroked his chin. "I see. Yes, not bad, George." He nodded briskly. "Ok. If the old chap is alive, see what you can do."

(30) "Political Intelligence."

"Political Intelligence", repeated A. and nodded.

(31) "Call me Clara", the girl said.

“Clara..." G. nodded. "It's a pretty name." 
A fim de melhor entender a problemática de nod em tradução, deve-se acrescentar a essa variedade e complexidade semântica o papel semiótico desse gesto nas culturas de língua inglesa. Nelas, nod é um elemento da linguagem não verbal que é relevante em termos de frequência e de significado múltiplo. É um gesto muito comum e com muitos significados; isto é, serve para muitos fins. Constitui um recorte linguístico e gestual próprio daquela cultura que difere do recorte da língua e da cultura portuguesa do Brasil.

Evidência disso é o fato de precisarmos recorrer a várias e longas expressões para abranger os diferentes aspectos semânticos desse monossílabo inglês de três fonemas. Vejamos alguns exemplos de tradução: balançar a cabeça, fazer um sinal com a cabeça, concordar movendo a cabeça, acenar com a cabeça, fazer um movimento da cabeça concordando, fazer que sim com a cabeça, concordar, assentir, balançar a cabeça em sinal de assentimento/aceitação. Algumas dessas possibilidades são um tanto desastrosas. Se analisarmos essas diversas opções, veremos que nenhuma é totalmente satisfatória, mas cada uma satisfaz um aspecto da totalidade do significado, sem entrarmos em questões de estilo e elegância da linguagem.

Para encontrar soluções adequadas, o tradutor deve ter consciência da complexidade e da potencialidade semântica do termo, bem como da ausência de um equivalente perfeito em português. Em seguida, deve analisar o contexto linguístico e situacional para escolher qual elemento é exigido ou sobressai como o mais importante para completar o significado da oração ou do texto em geral. Há contextos em que apenas o elemento físico "balançar a cabeça" é suficiente para a comunicação. Há outros em que a intenção ou o estado psicológico do falante, mais do que o gesto, é relevante. Então recorre-se a "concordar", “aceitar", "acenar", "cumprimentar" etc.

Para se fazer uma comparação adequada, além da equivalência de significado, se deveria perguntar qual o papel do gesto representado por nod no sistema semiótico da cultura de língua inglesa e perguntar também quantas vezes seria encontrada a expressão "balançar a cabeça" ou "concordar balançando a cabeça" em um texto de interação escrito em português. Seria interessante contar com um estudo comparativo da linguagem gestual dos falantes do português e do inglês. Temos, por exemplo, em português, "sacudir a cabeça" e "abanar a cabeça". Lendo a frase "Ele sacudiu energicamente a cabeça", ninguém ousaria pensar num gesto afirmativo de movimento 
vertical como seria nod. É um gesto negativo de movimento horizontal, que seria traduzido por "He shook his head."

O exemplo seguinte é uma boa ilustração de como sistemas semióticos se desencontram, trazendo implicações no uso linguístico. O contexto deste exemplo é o de um pai andando de motocicleta pelo campo com o filho e mostrando-lhe, entusiasmado, um melro de asas vermelhas, ao que o filho responde:

(32) "I've seen lots of those, Dad!"

“Oh!” I holler back. Then I nod. At age eleven you don't get very impressed with red-winged blackbirds.

A tradução adequada, de acordo com nosso sistema semiótico, será "sacudo/abano a cabeça" num movimento horizontal e não vertical, significando crítica e ao mesmo tempo conformidade.

Shrug participa da mesma característica de nod, isto é, a da produção de sentido por meio de um gesto. Aqui também ele pode ser um simples movimento corporal (o levantar e abaixar dos ombros) ou um movimento corporal $+x$ (onde $x$ é uma atitude, um estado mental).

Há ocorrências de shrug significando apenas o movimento corporal, bem menos frequentes, e não em situação de interação. São os exemplos:

(33) They shrugged their way through the dancers.

(34) She shrugged herself into the coat.

(35) ... shrugging the clothes together upon her body.

Sintaticamente, nas ocorrências outras com significado de movimento físico $+x$ ( $x$ = estado mental), shrug é intransitivo, como nos exemplos seguintes:

(36) "I'll talk to Willy, Felix."

F. shrugged.

"If that's the way you want it."

(37) "I'll call D. He'll take care of him."

G. shrugged.

"All right. Go ahead."

Shrug também pode ser transitivo, tendo shoulders como objeto direto. Exemplos:

(38) "What did you think?" 
The young man shrugged his shoulders. "You learn never to be surprised at anything in the house business."

(39) "Do you intend sending her to Buenos Aires?" "Perhaps not. It's an idea that occurred to me."

A. shrugged his shoulders.

Também à semelhança de nod, shrug tem uso bastante frequente em situações de interação. Nos exemplos colhidos, o termo ocorre como resposta direta a uma fala do interlocutor (exs. 36, 37, 38 acima). No ex. 40 não é uma resposta direta, mas uma expressão de reforço à própria fala.

(40) "My wife and children were casualties in a war... Yours-" $\mathrm{He}$ shrugged. "A vicious and empty waste."

Se shrug é igual a mover os ombros $+x$, qual é o significado de $x$ ? Não encontramos nos nossos exemplos uma diversidade tão grande como a encontrada em nod. Em geral, representa atitudes e sentimentos semelhantes, pertencentes ao mesmo campo semântico: indiferença, "sei lá", "não é comigo", “esquece/não tem importância", "não há nada que eu possa fazer". É o contexto situacional que faz sobressair um significado em vez de outros.

Em termos de tradução, diferentemente de nod, shrug tem uma expressão equivalente em português, "dar de ombros", que resume os dois exemplos do significado: mover os ombros expressando indiferença, "sei lá", "não importa" etc. Outras alternativas de tradução são: "encolher os ombros", "sacudir os ombros/com indiferença", "expressar indiferença encolhendo os ombros", que não nos parecem soluções satisfatórias.

A questão com “dar de ombros", que é uma equivalência correta, é o desequilíbrio de uso. Enquanto shrug é amplamente usado não só na língua escrita, mas também na língua oral, "dar de ombros" é uma expressão que, por ser inusitada, não tem o mesmo valor comunicativo.

$\mathrm{Na}$ tradução, além de "dar de ombros" ou "encolher os ombros", pode-se recorrer apenas ao elemento psicológico do significado para que a comunicação se faça com coerência.

Em relação a frown, a frequência de ocorrência desse item é muito menor que a dos outros verbos. Ocorre como verbo intransitivo, quer isoladamente - conforme exs. 41 e 42 - quer seguido de adjuntos que lhe esclarecem o significado — exs. 43 e 44. 
(41) "I hope he gets there all right."

D. frowned. "I know. I feel I ought to have gone with him."

(42) She frowned. "Must I hear it?"

(43) He frowned in astonishment.

(44) The teacher frowned impatiently at the students.

Aqui também o significado é igual a movimento corporal (franzir a testa) $+x$, onde $x$ é um estado mental que pode ser desagrado, zanga, preocupação, concentração, estranheza, perplexidade.

Os exs. 45, 46, 47 apresentam essa composição de significado.

(45) Some of his uneasiness seemed to communicate itself to the policeman. "That's odd", he said, frowning.

(46) D. lifted the telephone receiver. He held it to his ear for a long moment, frowning.

(47) She frowned with displeasure.

Como saber o estado mental por trás do gesto? Em alguns casos o contexto linguístico imediato, o adjunto adverbial, esclarece. Exemplos:

(43) He frowned in astonishment.

(44) The teacher frowned impatiently at the students.

(47) She frowned with displeasure.

Em outros - exs. 41, 42, 45, 46 - é o contexto linguístico adjacente ou situacional o responsável por definir qual o estado mental expresso por frown.

O exemplo (48) é um caso em que o movimento facial - franzir a testa - não está presente, mas apenas a atitude mental que ele representa de reprovação e desagrado.

(48) He frowns upon his daughter's smoking and drinking.

Nesses dois últimos itens - shrug e frown — em termos de tradução, chega-se às mesmas conclusões práticas que obtivemos a respeito de nod.

Embora algumas expressões em português sejam traduções adequadas para aqueles verbos, o tradutor deve estar consciente da sua complexidade semântica e da sua dependência do contexto pragmático. A interação só é representada efetivamente quando todos seus elementos são devidamente conhecidos e expressados. De posse desse conhecimento, o tradutor terá a opção de traduzi-los pelo seu corresponde gestual — "encolher os ombros" ou "franzir a testa", por exemplo — ou pelo estado 
BORDENAVE - Nod, shrug, frown:...

psicológico que eles expressam - "não se importar" ou "preocupar-se", por exemplo. Dessa forma, a comunicação da mensagem total é mantida. 